\title{
On-site Smart Operation and Maintenance System for Substation Equipment Based on Mobile Network
}

\author{
https://doi.org/10.3991/ijoe.v14i03.8103
}

Lin Cheng

Nanjing NARI Group Corp., State Grid Electric Power Research Institute, Nanjing, China Wuhan NARI Co Ltd., State Grid Electric Power Research Institute, Wuhan, China

\author{
Wenshan $\mathrm{Hu}^{(\varpi)}$ \\ Wuhan University, Wuhan, China \\ wenshan.hu@whu.edu.cn
}

Zhengyang Liu, Wei Cai

Nanjing NARI Group Corp., State Grid Electric Power Research Institute, Nanjing, China Wuhan NARI Co Ltd., State Grid Electric Power Research Institute, Wuhan, China

\begin{abstract}
The maintenance of substations is crucial for the safety of the electrical grid and power industry. However, for long time, the maintenance teams in the field and the experts in the power companies are divided. The data and expertise exchanges between the on-site maintenance teams and data center are delayed due to the lack of effective communication. This paper introduces an on-site smart operation maintenance system for substation equipment based on mobile network. It is able to establish real-time communication and data exchange channels between the maintenance teams and data center. It consists of an operation and maintenance system platform located on the data center side and smart operation and maintenance boxes with mobile APP which are carried to the field side by the maintenance teams. As the kernel of the system, the smart boxes are bridges between the data center and operation sites. On one hand, it is able to formally upload data to the data center in real-time. One the other hand, the operation and maintenance personnel are able to call for help from the resource on the data center anytime. Using the system proposed in the paper, both efficiency of the operation and maintenance and the normalization of the data can be improved.
\end{abstract}

Keywords-Operation and maintenance integration; mobile network; on-site operation and maintenance

\section{Introduction}

Power grid equipment maintenance is an important part of the management for power generation and transmission. It plays a significant role in improving the health of devices and ensure the safety of power grid. 
For a long time, substations' daily work have been gradually divided into operations and maintenance according to the responsibilities ${ }^{[1]}$. This division of labor plays an important role in the professional development of the business, and also in ensuring the safety of power grids in China. However, there are also problems of inefficient production operations and insufficient performance of human resources. Under the background that the power grid is more and more complicated and the requirement for safety and reliability is constantly increasing, the State Grid of China has proposed the task of "major overhaul" system construction to enhance the assets safety life management ${ }^{[2]}$, mainly by the integration management, operation and maintenance. According to the voltage level, the production system of power grid equipment operation and maintenance is carried out by the provincial and city maintenance sub companies. At present, the maintenance company uses the mode of "operation and maintenance team + substation" for the substations ${ }^{[3]}$. Each operation and maintenance team needs to manage several substations. Because of the complexity and great significance of the substation equipment, higher technical requirements are put forward for maintenance workers. Under the existing conditions, it is necessary to design a set of operation and maintenance integrated mobile platform ${ }^{[4-6]}$, which can not only reduce the labor intensity of the inspectors, but also ensure the quality and process standardization of the inspection and transportation.

Some literatures show that the assumption of mobile work platform has certain research basis: The related literature analyzes the information security of patrol mobile terminal based on Android platform. Engineer Jiang Houming and $\mathrm{Hu} \mathrm{mu}^{[7]}$ in Nari Group Corporation State Grid Electric Power Research Institute proposed a packetbased electric power industry technology for mobile work platforms. A method for positioning and supporting the work platform of a mobile workover rig is introduced by Lambert and A Jeff ${ }^{[8]}$. Nozawa and Masao ${ }^{[9]}$ studied the mobile work platform for use in Apple Orchards.

However, for the power operation and maintenance in China currently, mostly data are collected and inputted manually, which causes the problems such as low efficiency of data collection and low reliability of devices in operation and maintenance. In the power industry, the power grid equipment is normally diversely located, while the number of experts is limited ${ }^{[10,11]}$. Therefore, it is impossible for every substation to have on-site experts when there are problems. The dispersion of power grid equipment and the disconnection between the field side and the center side leads to that the operation and maintenance work cannot efficiently and effectively use the central side of resources. The decision-making and expert guidance of central side cannot be effectively transmitted to the field, where the maintenance team may not have the knowledge and expertise to solve all the complex problems. Therefore, the intelligent operation maintenance and control is an important field of application and control of new information communication technology platform construction ${ }^{[12,13]}$, and it's urgent to carry out the research on intelligent system of on-site.

The applications of wireless transmission technology are more and more accepted, which is easy to install, flexible and cost-effective. On the base of the latest mobile Internet technology and big data technology, this paper proposes an online intelligent operation and maintenance system based on mobile network. Every operation and 
maintenance team carries a hand-held device for power data acquisition and analysis in the system which is called smart operation maintenance box. As the bridge between the center side and the field side, the box is designed to unify all kinds of charged detection device and mobile terminal communication interface specification, and all kinds of charged detection device detection record data format. For the center side, the on-line operation and maintenance can communicate with the workers on site, and provide technical supports through the smart operation maintenance box. For the field side, they can use the rich resources to complete the operation maintenance task. It can improve the efficiency of on-site operation, provide a system support for the application of new information technology in on-site application and control, and strengthen the remote control and real-time technical support ability of on-site operation and maintenance.

\section{Purpose and necessity of smart operation and maintenance box development}

\subsection{Existing problems of on-site maintenance operation}

As an important parameter of equipment status, the equipment state detection data is essential for carrying out the state evaluation of power grid equipment ${ }^{[14,15]}$, including inspection, operating conditions, charged detection, power failure routine test ${ }^{[16,17]}$, etc. With the development of smart grid construction and condition-based maintenance (CBM), there are still some deficiencies in the acquisition and utilization of equipment state inspection data on the site.

1. Unreliable data of the device status. The completeness and correctness of data collection depend heavily on the professional level of maintenance workers. With the rapid development and expansion of the power grid, the lack of experienced workers has become more and more severe.

2. Unnormalized data of the device status. At present, there are all kinds of charged detection devices. The levels of automation for these devices are different. Some devices have the records in paper, which caused non-standard records of data and low utilization efficiency. Though the same item is recorded, the instrument output data format of different manufacture is different.

3. Inefficient input of the device status data. At present, the test data of live inspection mainly depend on the manual record of professionals on site. The result of measurement cannot be conveniently archived and analyzed, which leads to higher costs of operation and maintenance, low working efficiency, and low utilization efficiency of data.

4. Dispersed information and the poor cooperation between the center and the site. Device status data is mainly processed depending on manual arrangement, analysis and application, which lacks of effective and timeless automation evaluation, diagnosis and analysis. The field side cannot use the rich data resources of the center side, the central side cannot conduct strong guidance on field test, leading to poor interoperability. 


\subsection{Solution based on wireless network and mobile platform}

Production management system (PMS) is designed to manage and track various production and related activities in manufacturing companies, which is based on cloud and web. While the operation management system can create work orders to assign personnel and other resources, as well as recording the location and inventory. With the support of PMS ${ }^{[18]}$ and OMS(Operation Management System ${ }^{[19,20]}$, the equipment status information is dispersed in different systems, not only lacking interconnection with the central side of PMS and OMS, but also bring barriers between systems, which leads to so called "information islands".

In order to address these problems, the on-site smart operation maintenance system for substation equipment is developed based on new information and communication technologies. Using the mobile technologies, the center side and the field side are connected. On one hand, the on-site data can be automatically uploaded to the data center in the power company. On the other hand, the on-site teams can always call for help from the experts in the power company by organizing live video conference.

\section{Overall architecture of system}

\subsection{Basic structure of system}

The overall structure of the proposed on-site intelligent operation maintenance system of power system is shown as Figure 1.

The system structure is divided into the center side and the field side. In the field side, there is the smart operation and maintenance box, which works as the bridge between the two sides, and is the most important part of the system. In addition, there are the on-site operation and maintenance devices, which can complete the detection through various technologies. In the center side of the power grid, there is the integrated operation and maintenance platform, which provides the relevant guidance and supports for the workers on site through the mobile communication network.

\subsection{Operation and maintenance platform on center side}

The operation and maintenance platform on the center side takes full use of the advantage of power grid center data, to manage and guide the operation maintenance on site. It collects test data of the smart operation maintenance box uploaded from the site through the network, and then store it in the database. At the same time, it makes decision and provides support according to the operation on site, and issues them to the site side to guide the on-site workers. When on-site workers face difficulties, they can call the center side for help anytime through the mobile network. After receiving the call, the center side management teams will organize the corresponding experts and provide on-site guidance through the video conference. 
Paper-On-site Smart Operation and Maintenance System for Substation Equipment Based on Mob...
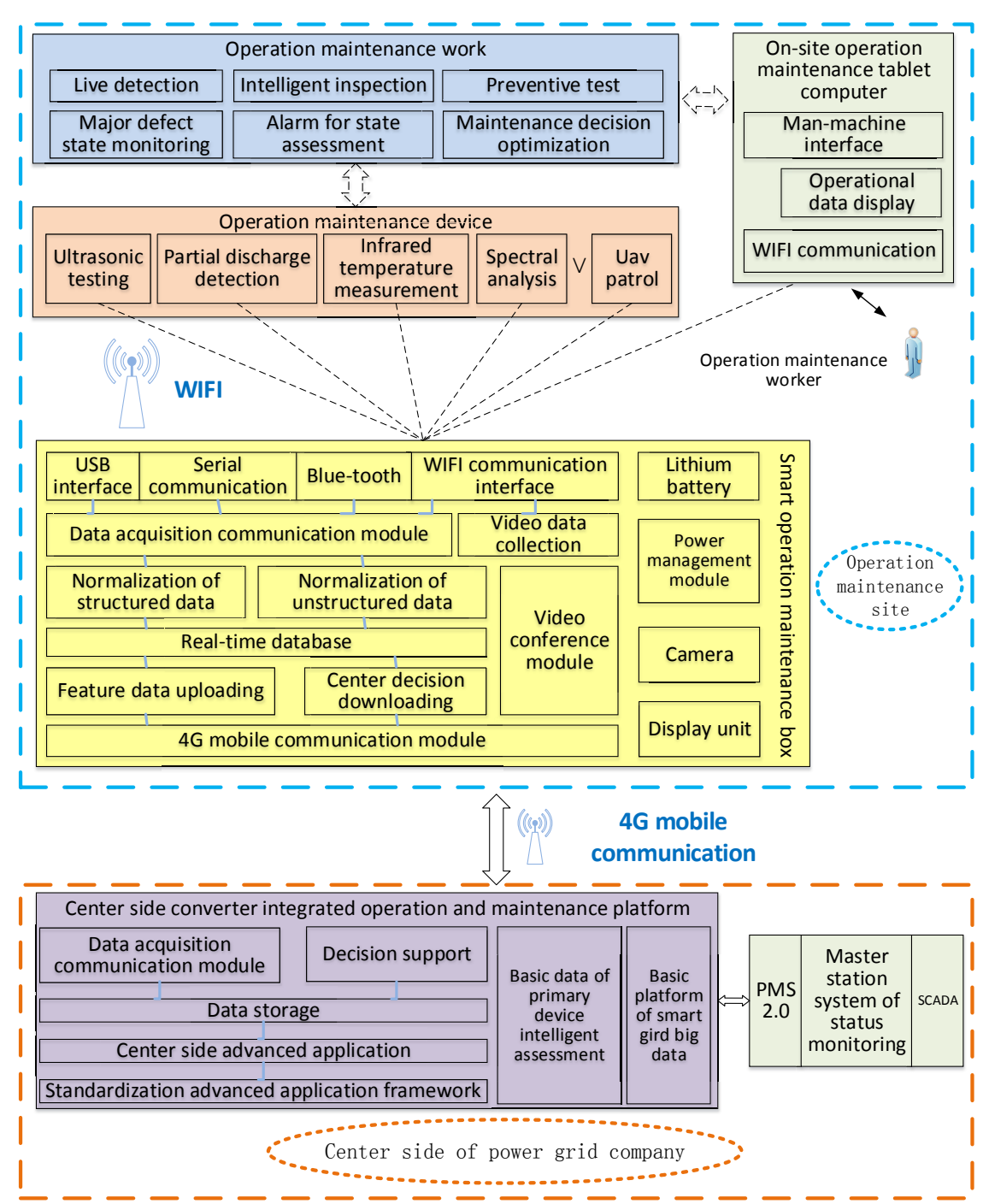

Fig. 1. System Architecture

The center side system sets the standardized advanced application framework which can be embedded with many kinds of advanced applications, such as primary equipment evaluation diagnostic service, maintenance plan decision service etc. These applications provide guidance for the maintenance in a higher level based on the test data collected.

At the same time, the center side integration operation maintenance platform of substation can be connected with the big data of power grid, such as PMS2.0 system, statues monitoring master system and so on, which provides excellent big data support for the generation of operation maintenance decision. 


\section{Design of smart operation maintenance box}

\subsection{Smart operation maintenance box and integral management and control platform}

As is shown in Figure 2, the management platform equipped with the smart operation maintenance box is proposed in this paper.

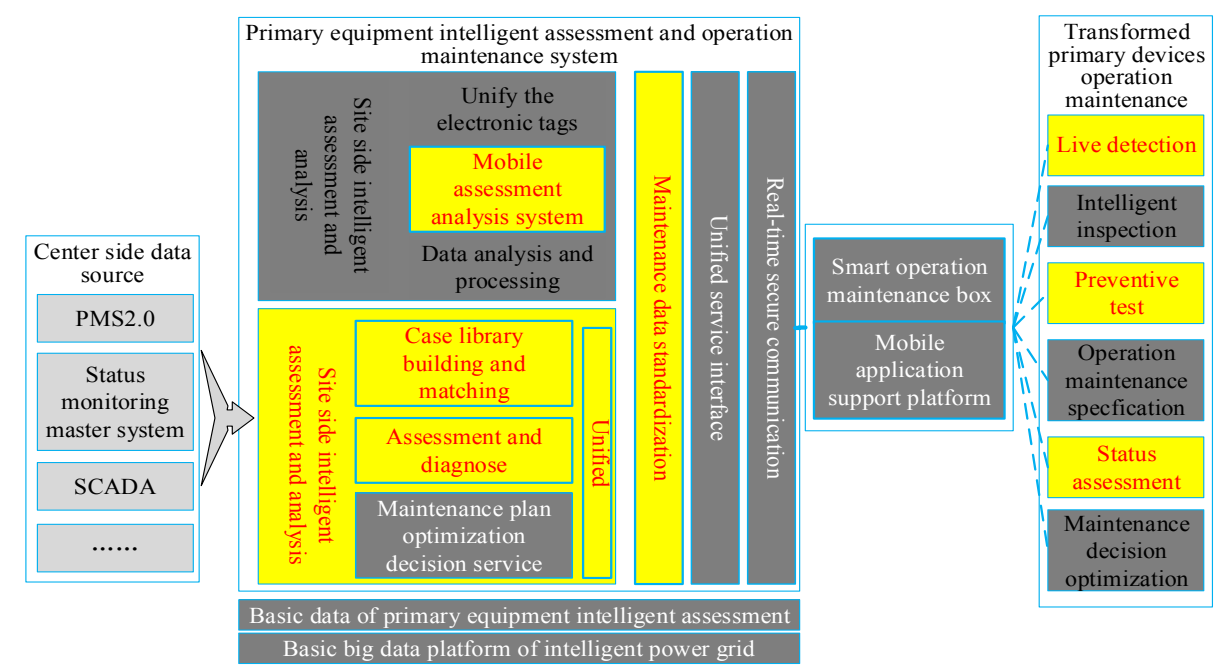

Fig. 2. Architecture of operation and maintenance system

On site, the box is connected with the power detection equipment through the wireless network, and communicates through the unified protocol. When transport inspection personnel is in any part of the maintenance work, the data obtained can be uploaded to the box for preliminary analysis and storage. After the information of the box is normalized, it is uploaded directly to the data center of Power Grid Corp through the mobile wireless communication network for the intelligent evaluation and inspection system.

Similarly, the big data and calculation source of the center side can interact with the maintenance work on site through the smart operation maintenance box. For example, the senior application center side can analyze the locale uploaded data, and through the case library, it can be matched and analyzed. Once abnormal data or emergency equipment fault occurred, it can directly notify the maintenance teams to carry out intervention.

When the operation and maintenance personnel faces technology difficulties, he can call for the site guidance of the center side professor by video conference. 


\subsection{Software and hardware architecture of the box}

Hardware architecture. Taking the performance and energy consumption into consideration, OMAPTM 5432 platform is applied to the smart operation maintenance box, and Exynos5250 with ARM CorTex-A15 framework to CPU, with the frequency of $1.7 \mathrm{GHz}$.

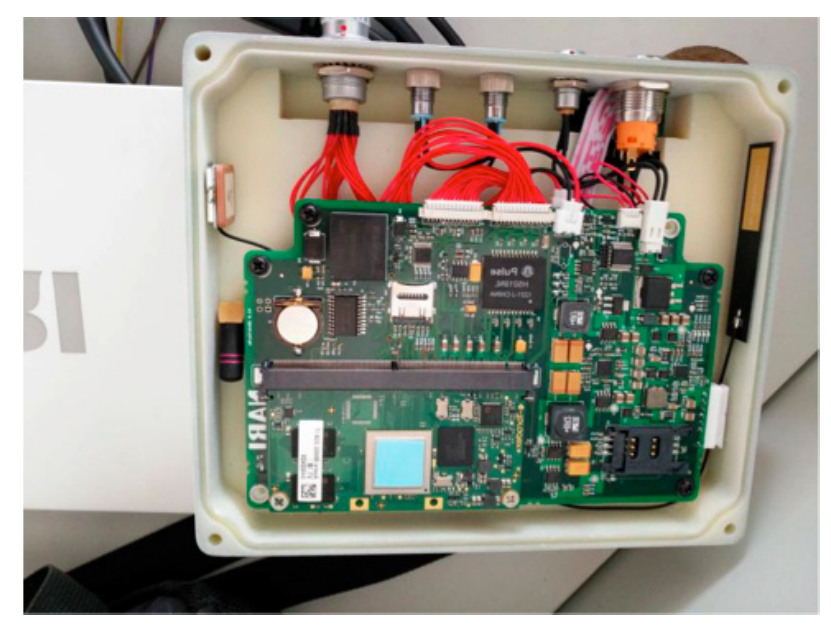

Fig. 3. Hardware circuit of smart operation and maintenance box

In the hardware interface, the platform is equipped with a dedicated TI 2D BitBlt graphics accelerator to support the real-time data monitoring in this item, and support three cameras and four display screens operating at the same time, which achieves video conference directly without the tablet computer support. The box is embedded with WIFI $\square$ Bluetooth $\square 4 \mathrm{G}$ and 10M/100M adaptive network communication module, and can communicate with a variety of testing devices and the data center. The hardware circuit is drawn as Figure 3.

Software architecture. In the aspect of software, Android 4.2.2 Jelly Bean is applied to this system, which is based on Linux 3.4.35 system kernel, using gcc 4.4.1 to achieve cross compile. The file system adopts Ramdisk and Ext4 combination. The software architecture of the operation maintenance box is shown in Figure 4.

The software architecture integrates various communication driver management modules, and supports a varieties of communication equipment and protocol through the multi-layer structure. Various external device drivers are deployed, such as camera, display, and USB storage devices etc. The resource of kernel layer is provided by Android system, and the function of open source operating system has been tailored to form its own special system.

The application layer module is mainly composed of independent developed modules, such as video conferencing client, data processing, data management and testing equipment management and other modules. With the support of algorithm library, these modules realize the main functionalities such as data acquisition, storage, uploading and interacting with the center side etc. 


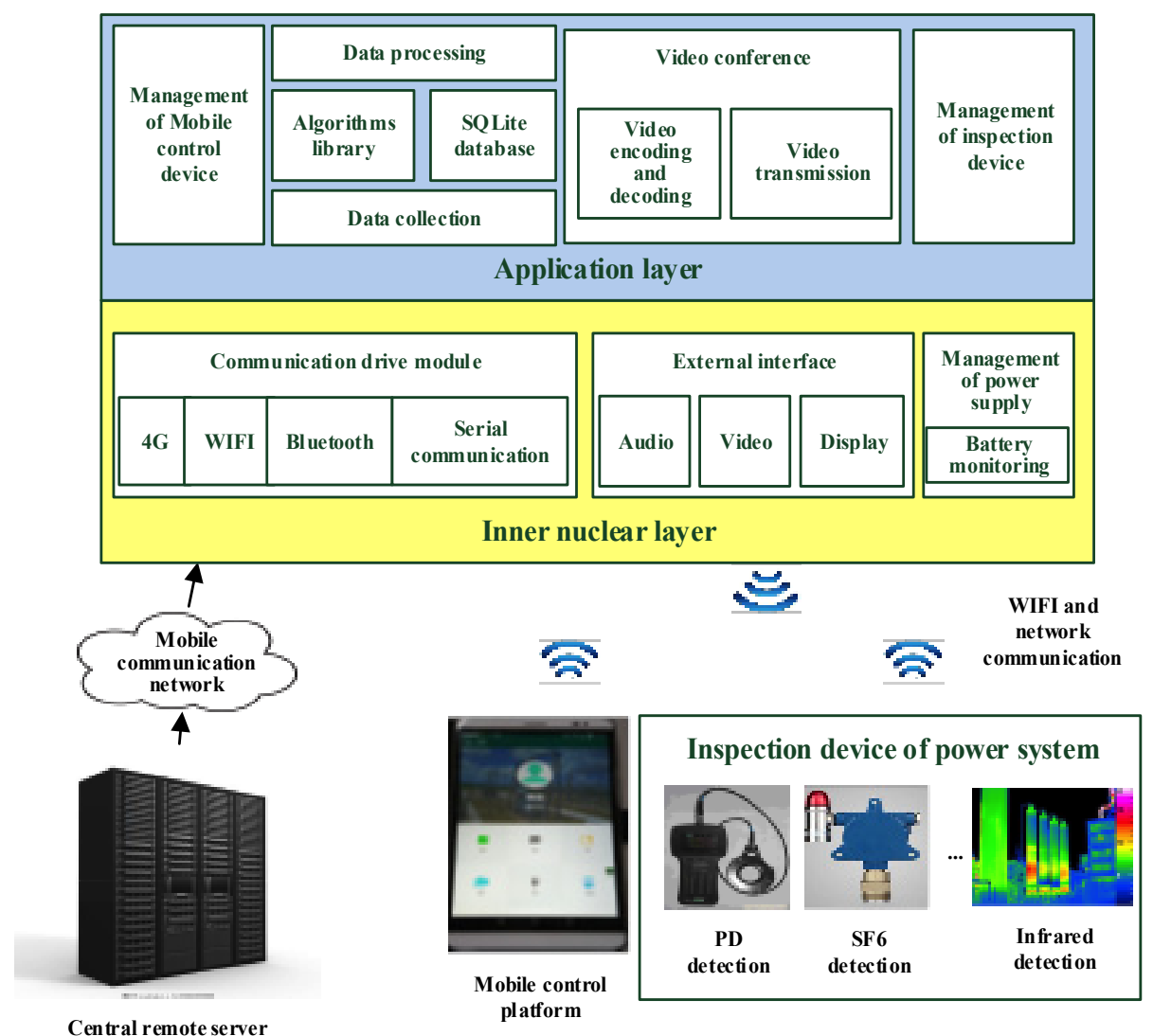

Fig. 4. Software architecture of smart operation and maintenance box

\subsection{Work flow with smart operation maintenance box}

During the operation maintenance, it needs to be ensured that the workers and equipment on site can be connected real-time with the integral control platform, big data and professors in center side. On the one hand, the on-site test data can be uploaded timelessly. On the other hand, the decision in the center side can be issued timelessly, which achieves resource sharing and advantages complementary. As is shown in Figure 5, the management platform equipped with the smart operation maintenance box is proposed in this paper.

On the center side, manager set maintenance tasks through the integral control platform, such as the converting stations need to be inspected and the operation maintenance test to be done, and so on. 


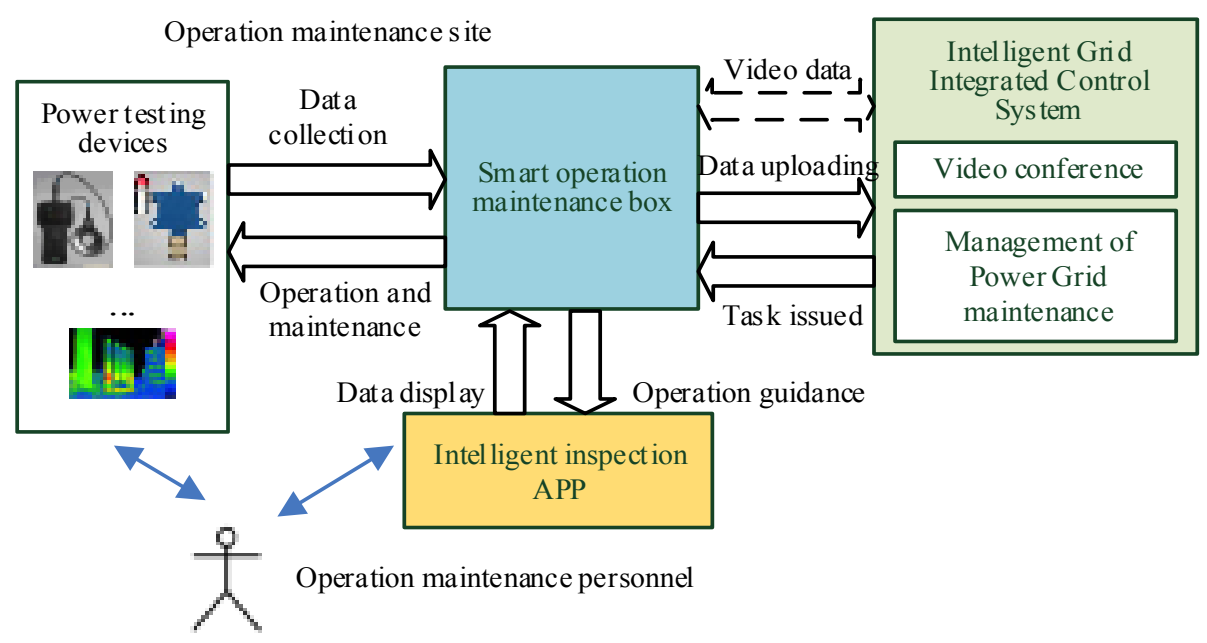

Fig. 5. On-site operation with smart operation and maintenance box

Operation and maintenance personnel lay out the smart operation and maintenance box and power detection devices, then the box sets up the WIFI and is connected with the devices. According to the guidance on the box, the workers operate the detection device, and the test data can be stored in the box. After that, the test report can be generated automatically and the data can be one click uploaded when the worker touches the tablet computer. Thus the labour intensity of the workers can be reduced substantially by using the smart operation maintenance box.

\section{$5 \quad$ Case study using smart operation maintenance box}

It can greatly improve the efficiency of maintenance reliability and standardization of data to use the smart operation maintenance box. The smart box and platform has been utilized in the practical operations in Fujian, Zhejiang, Shandong provinces, and is expected to be applied in Sichuan, Shanghai, Gansu, Chongqing etc. in the future. In this paper, the live operation maintenance daily work of substation is taken as an example to introduce the work instance of the smart operation maintenance box and the integration manage platform.

In the operation maintenance integration system, there are two kinds of users according to their responsivities. One is the project manager, who needs to manage substation testing project comprehensively, assign and send tasks to maintenance personnel on site, check the data collected and supervise the progress. The other one is operating maintenance team. The members use the APP to download testing tasks and upload data, which achieves the data exchange between the client-side and site, and display and feedback to client in real time. The work procedure of them is as shown in Figure 6. 


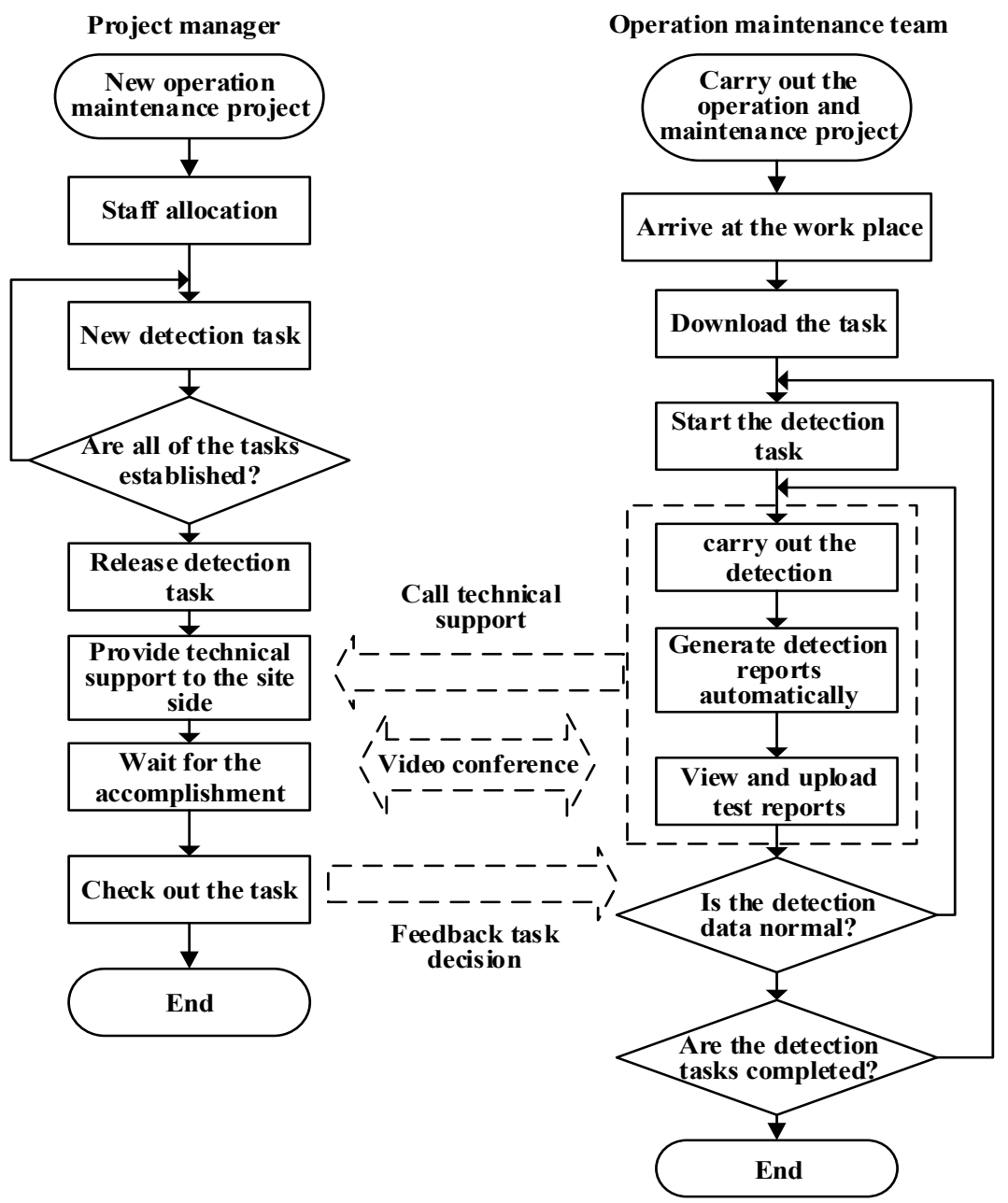

Fig. 6. Work-flow of operation and maintenance work

\subsection{Working instance of project manager}

Project manager works in the center-side of Power Grid Company. The work procedure is shown in the left half of Figure 6.

Firstly, he inputs the accounts and passwords to login the operation maintenance integration platform, then enter the project information in the Web interface, establish the specific projects and endow them with importance. After that, the manager allocate relevant personnel for the project.

After the detection project is established, the corresponding tasks will be assigned further, such as infrared detection, ultrasonic and SF6 gas detection, etc. As is shown in Figure 7(a), an infrared detection task is established during the routine inspection in Jinan. The project manager can input the tasks into the system and then post them out. 


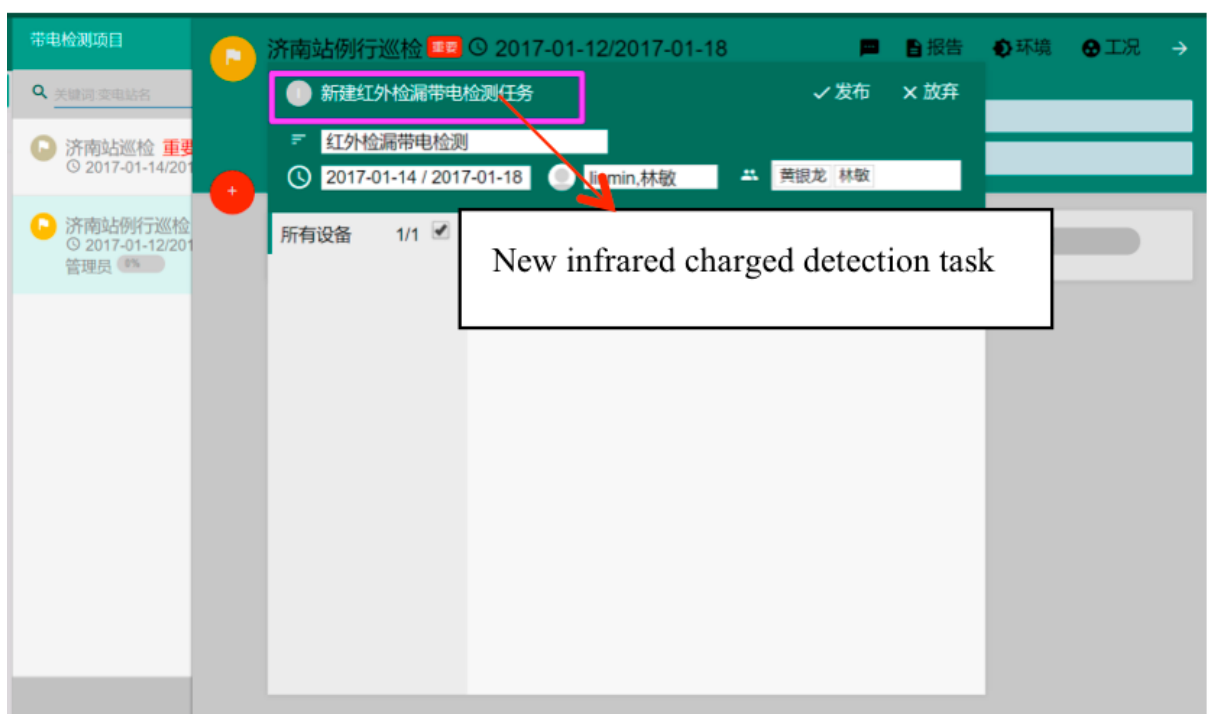

(a) Creating operation and maintenance project

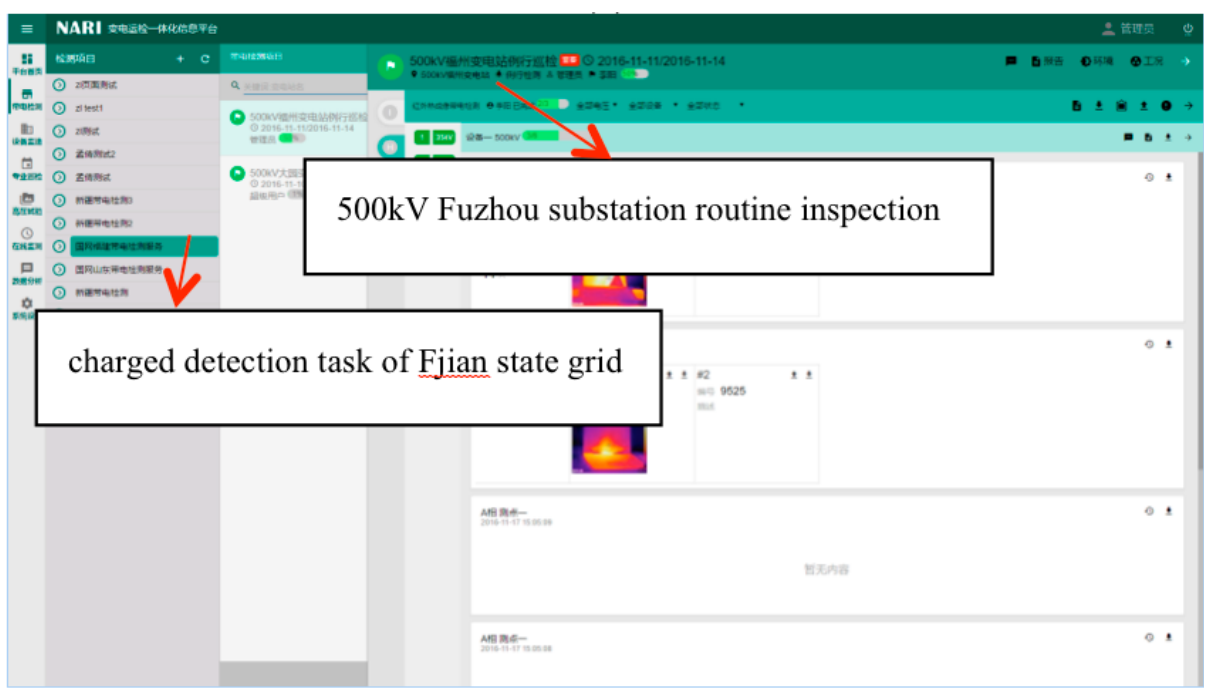

(b) Assigning infrared measurement task

Fig. 7. Web interface for project manager

After that, system will push notifications to the maintenance team, who is going to work on site with test devices and the smart operation maintenance box. At the same time, the manager will monitor the team's work, in order to respond the call request once they are faced with technical difficulties. Then arrange a video conference between the technical professors and maintenance personnel to solve the problems. 
System will push notifications to the project manager when the maintenance task is accomplished. The detection reports can be checked and evaluated whenever, such the infrared detection report of 500kV Fuzhou substation in Figure 7(b). Then the manager sends the feedback decision information to the maintenance team.

\subsection{Working instance of maintenance team}

The maintenance team will arrive at the work place carrying with the test devices, the smart operation maintenance box, and a tablet computer, after receiving the tasks. They can firstly run the operation maintenance APP, which communicates with the box through WIFI, and then download the tasks. As is shown in Figure 8(a), the content, importance and completion of the task an be displayed in the list.

Figure 8(b) is the preparation information of the infrared detection project. The operation maintenance personnel needs to complete all the inspection options and check the corresponding dialog box before they proceed to the next step.

Taking the infrared detection as an example, the team can operate the infrared imager through the APP to take photo of the power devices. The infrared imager is connected with the box automatically, and the photo will be stored in the file system of the box. After the infrared detection is completed, the maintenance personnel can browse through the test data and chose the appropriate photo to be input into the system as the test data, as is shown in Figure 8(c).

If any difficulties occurs during the work, they can call the manage control integration platform in the Power Grid data center through the smart operation maintenance box, and receive the real-time guidance. Thus more time will be saved and the efficiency will be improved accordingly.

When all of the tasks are accomplished, the experimental reports will be generated automatically in the box, which will be displayed on the man-machine interface, as is shown in Figure 8(d). The operation maintenance team-workers check out the data of the report, and if data is confirmed, they will touch the "task submission" button to upload the test report to the database of center side.

\subsection{The advantages of using the smart operation maintenance box}

According to the working instance, the advantages to apply the box to the power system operation maintenance work are listed as followings:

Firstly, the work of the project manager is simplified. The manager only needs to manage and send the project tasks through the Web platform, and organizes the experts to carry out technical guidance for operation maintenance on site by telephone or video conference when necessary. Secondly, it can release the stress of the workers, and promote the efficiency. With the help of the experts through the video conference, the requirement for operation maintenance workers can be downgraded, which means the cost cutting for the power companies. Moreover, the storage of data is more unified. They can be presented to the users through a unified web interface. 


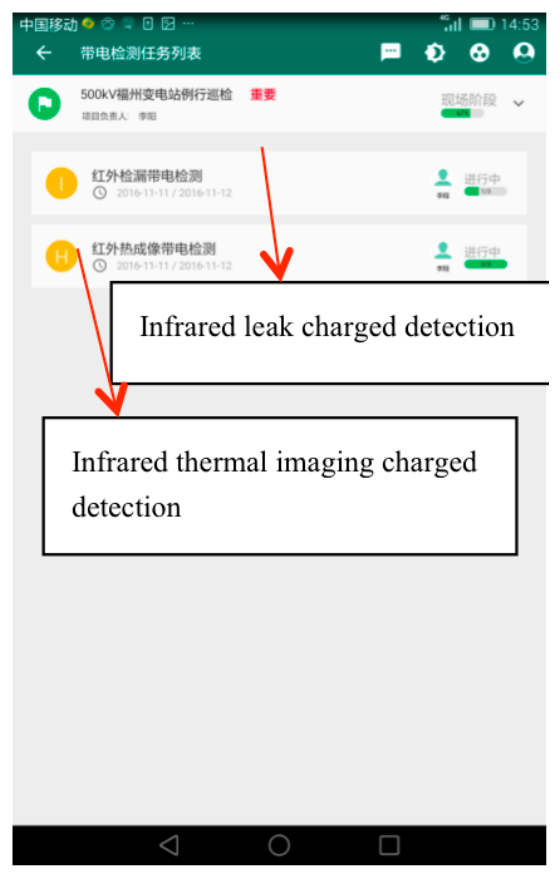

(a) Checking tasks

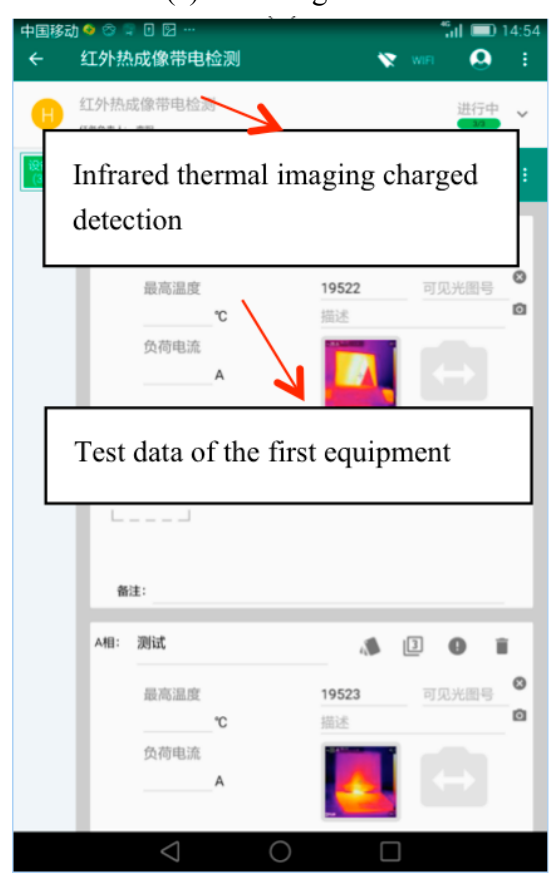

(c) Data input for infrared measurement

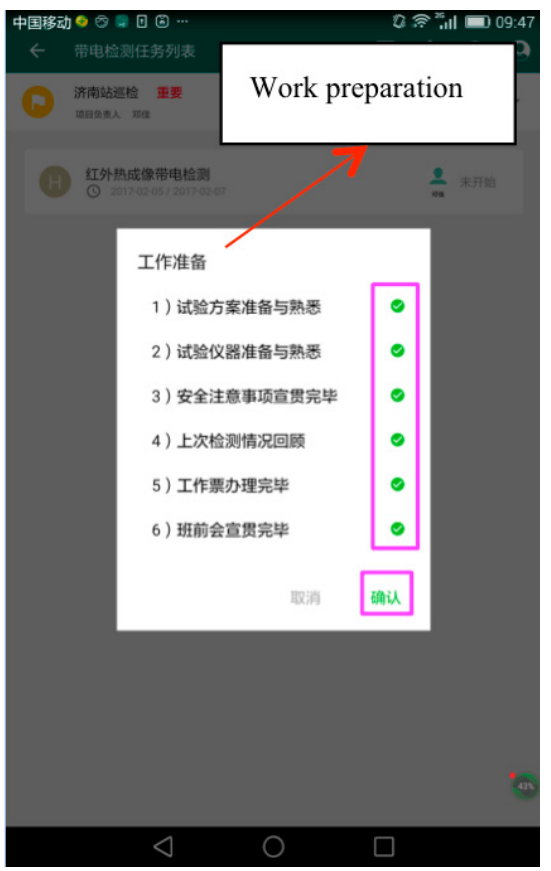

(b) Help information

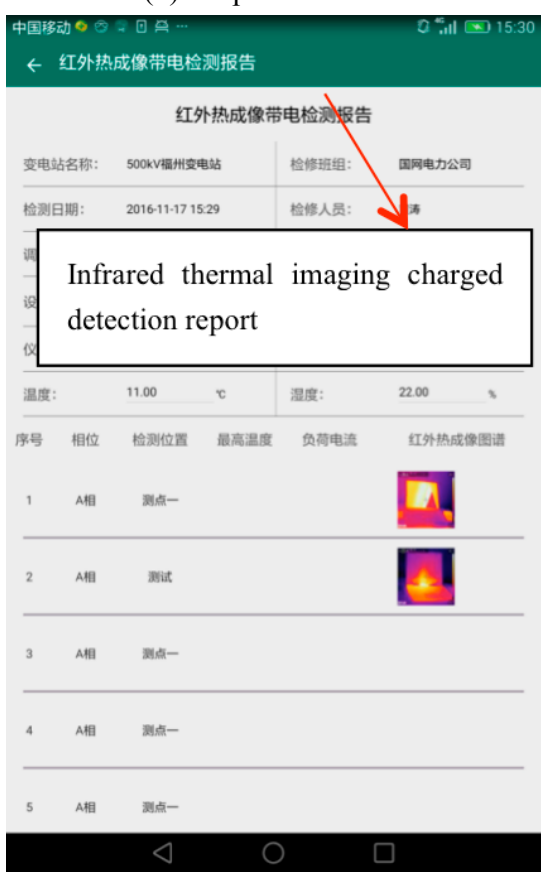

(d) Checking report

Fig. 8. App Interface for on-site team 


\section{Conclusion}

In this paper, the on-site smart operation maintenance system for substation equipment based on mobile network as well as its smart operation maintenance box is proposed. As the bridge between the communication and data, the box is connected with the detection devices through WIFI, and communicates with unified protocol. The manager releases tasks on the operation maintenance platform and the maintenance personnel downloads it, then operates test equipment to complete the work with the help of the intelligent operation maintenance APP. The test data generated during the process will be upload to the control platform via a unified interface. It promotes the efficiency of operation maintenance work drastically and reduces the worker's stress to apply the system to power grid maintenance work. Moreover, the reliability and normative can be ensured.

\section{$7 \quad$ Reference}

[1] Akinyele, D. O., \& Rayudu, R. K. (2014). Distributed photovoltaic power generation for energy-poor households: The Nigerian perspective. Power and Energy Engineering Conference. IEEE, 2014:1-6.

[2] Ferri, M., Pinna, D., Dallago, E., \& Malcovati, P. (2010). Photovoltaic energy harvester with power management system. Journal of Sensors, 2010, (2010-10-26), 2010(1), 23-59. https://doi.org/10.1155/2010/349389

[3] Partin-Vaisband, I. (2017). Automated Design of Stable Power Delivery Systems for Heterogeneous IoT Systems. on Great Lakes Symposium on Vlsi. ACM, 2017:381-386.

[4] Atlason, R. S., \& Unnthorsson, R. (2013). Operation and Maintenance in Icelandic Geothermal Power Plants: Structure and Hierarchy. ASME 2013 Power ence .2013:V001T05A007.

[5] Kang, S. J., Moon, J. C., Choi, D. H., Choi, S. S., \& Woo, H. G. (1998). A distributed and intelligent system approach for the automatic inspection of steam-generator tubes in nuclear power plants. IEEE Transactions on Nuclear Science, 45(3), 1713-1722. https://doi.org/10.1109/23.685293

[6] Peng, C., Fan, J., Fan, Q., Huang, D., Zhao, D., \& Peng, C., et al. (2017). Design and analysis of intelligent operation and maintenance platform system. Chinese Control Conference. 2017:7376-7381.

[7] Jiang, H. M., Mu, H. U., Jia, W. U., \& Dan, S. U. (2015). A power mobile work platform based on packet technology. Computer \& Modernization.

[8] Lambert, J. A., Garrett, J. C., Cambern, K. L., Ferland, J. M., Furnish, J. D., \& Johnson, D. W., et al. (2011). Automated system for positioning and supporting the work platform of a mobile workover and well-servicing rig. WO, US 8006751 B2[P]. 2011.

[9] Nozawa, M. (2010). Development and improvement of mobile work platform for use in apple orchards. Japanese Journal of Farm Work Research, 41(2), 68-73. https://doi.org/10.4035/jsfwr.41.68

[10] Tange, M., Katori, H., Nakagawa, Y., Noguchi, H., \& Youssef, M. G. (2000). An integrated digital control and protection system for substation automation. APSCOM $2000-5$ th International Conference on Advances in Power System Control, Operation and Management . IET Digital Library, 2000:465-468. https://doi.org/10.1049/cp:20000444

[11] IBM Cloud Manager with OpenStack for Power, Quickeasy V D A. IBM Cloud Manager with OpenStack for Power, V4.1 delivers a quick and easy, multi-platform cloud solution for IBM Power Systems servers[J]. Ibm Corporation. 
[12] Dv, E., Biglari, H., Engstedt, S. M., \& Ab, E. U. (2001). An operation and maintenance platform based on enterprise javabeans.

[13] Dulman, S. P. (1998). Maintenance operations console for an advanced intelligent network. US, US 5802146 A[P]. 1998.

[14] Amstein, P. R., Blumer, T. P., Coburn Iv, A. L., Forgaard, R. J., Schulert, A. J., \& Stefan$\mathrm{ik}, \mathrm{T}$., et al. (1998). Computer system and computer-implemented process for creation and maintenance of online services. US, US 5793966 A[P]. 1998.

[15] James, R. E. (2010). Discharge detection in high-voltage power transformers. Proceedings of the Institution of Electrical Engineers, 117(7), 1352-1362. https://doi.org/10.1049/piee.1 970.0259

[16] Kitayama, S. (1995). Digital transmission apparatus for subscribers having switching function from active transmission line to protection transmission line. US, US $5452286 \mathrm{~A}[\mathrm{P}]$. 1995.

[17] Elder, D. W., \& Bruno, F. (2008). Method for detecting a discharge condition fault in an electrical system of a vehicle or piece of machinery. US, US7427865[P]. 2008.

[18] Harhalakis, \& George. (1984). An integrated production management system for engineered equipment. Proc Natl Acad Sci U S A, 101(7), 2673-2677.

[19] Hoshino, M., \& Sato, M. (2003). Mobile terminal and moving body operation management system. US, EP 0745959 B1[P]. 2003.

[20] Yin, C., Yin, S., \& Liu, F. (2009). Integrated production operation management system for assembly workshop of automotive air-conditioning. Computer Integrated Manufacturing Systems, 15(3), 544-552.

\section{Acknowledgment}

This work is supported by State Grid Corporation of China Science and Technology Project under 52130415000W.

\section{Authors}

CHENG Lin is with Nanjing NARI Group Corporation State Grid Electric Power Research Institute, Nanjing 211000, China and with Wuhan NARI Limited Liability Company, State Grid Electric Power Research Institute, Wuhan 430074, China.

HU Wenshan is with the School of Power and Mechanical Engineering, Wuhan University, Wuhan 430072, China.

LIU Zhengyang is with Nanjing NARI Group Corporation State Grid Electric Power Research Institute, Nanjing 211000, China and with Wuhan NARI Limited Liability Company, State Grid Electric Power Research Institute, Wuhan 430074, China.

CAI Wei is with Nanjing NARI Group Corporation State Grid Electric Power Research Institute, Nanjing 211000, China and with Wuhan NARI Limited Liability Company, State Grid Electric Power Research Institute, Wuhan 430074, China.

Article submitted 12 December 2017. Resubmitted 21 January 2018. Final acceptance 05 March 2018. Final version published as submitted by the authors. 